\title{
Assessment of Antimicrobial, Anti-Inflammatory Activity and Docking Study of Novel 2-(Arylimino)-5-(Indole-2-Yl-Methylidene)-1, 3-Thiazolidine-4-one Derivatives
}

\author{
Neetu Chopra, Kiranpreet Kaur, Sandeep Kaur \\ Department of Pharmaceutical chemistry, \\ Rajendra Institute of Technology and Sciences (RITS), Sirsa, Haryana, India
}

\section{ABSTRACT}

A novel series of 2-(arylimino)-5-(indole-2-ylmethylidene)-1,3-thiazolidine-4-onederivatives were synthesized and screened for their anti-inflammatory and analgesic potential. The structures of newly synthesized compounds were confirmed by their analytical and spectroscopic data using IR and $1 \mathrm{H}-$ NMR. The novel compounds were evaluated for their anti-inflammatory potential using carrageenan induced paw edema model and analgesic activity using acetic acid induced abdominal writhing test. Three compounds $4 \mathrm{~g}, 4 \mathrm{~m}$ and $4 \mathrm{o}$-alleviated inflammation more than the standard drug Diclofenac Sodium. The synthesized compounds also showed significant analgesic activity. Insilicomoleculardocking studies of the synthesized compounds were done on crystal structure of Cyclooxygenase-2using Glide version 5.0 following the standard procedure recommended by Schrodinger to study their observed activity, which revealed a significant correlation between the binding score and biological activity for these compounds. Maximum Glide score was obtained for compound 4o having a value of -7.42. This compound showed one interaction with the enzyme.

Keyword: Indole, Diclofenac Sodium, In-Silico, NMR, Pseudomonas aeruginosa, Escherichia coli, Candida albicans, Cyclooxygenase-2

\section{INTRODUCTION}

Indoles are natural organic compounds with an aromatic heterocyclicstructure that are widely used in the synthesis of pharmaceuticalagents. ${ }^{[1]}$ Many synthesized derivatives have potent activity against fungi,viruses and Leishmania parasites as well as
Gram-positive and Gramnegativebacteria and mycobacterial species. ${ }^{[2-4]}$ Recently,much attention has been paid to indole core derivatives due to theirdiverse biological activities, for instance, the inhibition of bacteria, viruses, leishmania parasites and cancerous cells. ${ }^{[5-6]}$ Indolemoiety has been employed in the designing of new heterocyclic compounds with diversebiological and pharmacological properties like antimicrobial, antitubercular, antimalarial, antitubulin, $\alpha$-glucosidase inhibitors, antioxidant and fluorescent metal probes to sense molecularrecognitions. ${ }^{[7-15]}$ Theindole moiety is found in numerous natural and unnatural products and is an important building block of several families of alkaloids. Probably the best-known compound containing the indole structure istryptophan, which is an essential amino acid.Considerable synthetic attention has been directed at the development of efficient methods toward the construction and derivatization of indole-containing compounds, as this important subunit constitutes the core of a plethora ofbiologically active natural products. Accordingly, after 100 years of intensive research, a variety of well established methods for elaborating and functionalizing indoles are available.Acute and chronic inflammation and different type of arthritis are the inflammatory disorders, which are a big blow to humanity and continual search for newer nonsteroidal anti-inflammatory agents is the only way to fortify against this awful threat. In thelight of above report and also in continuation of our laboratory work on chemoselective reaction of indole derivatives, a drug strategy has been planned to synthesize several indole derivatives possessing thiazolidinone moiety withthe hope to get better anti-inflammatory 
molecules. ${ }^{[16-18]}$ Our research group has recently developed a methodology for synthesis of thiazolidinone derivatives of indole which are well known to introduce many interesting biological and pharmacological activities. Due to the wide existence and the important physiological activities of these indole compounds, the search for their specific receptors has been met with increasing attention. The design of biological probes for indole-binding proteins relies mainly on functionalized indole derivatives.Various approaches have been adopted to examine the substrate-binding properties of the biological receptors of indole compounds.

\section{Material and method Chemistry}

The chemistry of indoles has been of increasing interest, since several compounds of this type possess diverse biological activities. Also it has been reported that thiazolidinone derivatives of indole are well known to introduce many interesting biological and pharmacological activities. Based on these findings a synthesis of some new indole incorporated into other heterocyclic are carried out for the purpose of evaluation as antimicrobial agents.

In the present study 2-(heteroarylimino) thiazolidin-4one derivatives have been synthesized. The synthesis consists of three steps, Reaction of aromatic amine with chlorocetyl chloride, Cyclization of 2-chloro-N(etheroaryl)acetamide in the presence of ammonium thiocyanate to form the thiazolidinone, in the last step 2-( heteroarylimino) 5-arylidine thiazolidin-4-ones are prepared by Knovenagel reaction.

The synthetic procedures were carried out by reacting the appropriate amine with chloroacetylchloride in DMF at room temperature. Chloroacetyl chloride is a versatile reagent and has been extensively used in organic synthesis. It is primarily used as an acylating agent. The multi-functional nature of $\mathrm{ClCH}_{2} \mathrm{COCl}$ has made it a suitable two-carbon building block for cyclization. Numerous cyclic compounds, especially heterocycles, have been prepared through the use of the reagent. Chloroacetyl chloride is also a valuable precursor for monochloroketene and occasionally serves as a chlorinating agent. After completion of the reaction, which is usually two hours, cyclization of 2chloro-N-(etheroaryl)acetamide in the presence of ammonium thiocyanate, in refluxing ethanol, afforded in excellent yield and purity the 2-( heteroarylimino)thiazolidin-4-ones. Then 5-arylidine products were obtained by Knovenagel reaction.
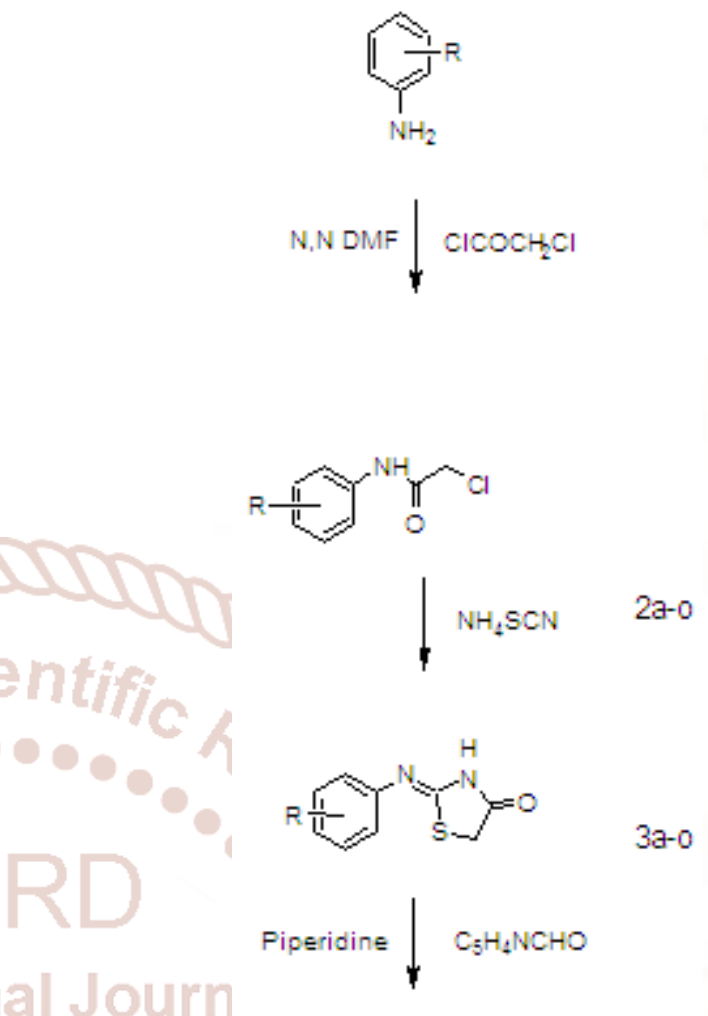

$a-0$

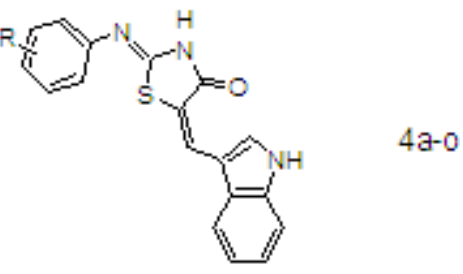

All the reactions were carried out under prescribed laboratory conditions. All the reactions requiring anhydrous conditions were conducted in flame dried apparatus.

\section{General procedure for synthesis of subtituted indole-3-carboxaldehyde}

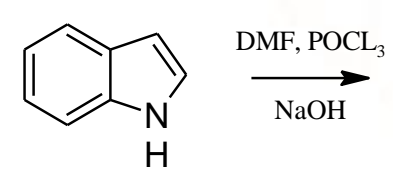<smiles>O=Cc1c[nH]c2ccccc12</smiles>

To dimethyl formamide in ice bath, $\mathrm{POCl}_{3}$ was added drop wise by maintaining temperature below $10^{\circ} \mathrm{C}$. After the addition, the mixture was stirred for $0.5 \mathrm{~h}$. To this formylationcomplex,solution of indole in DMF was added. During addition temperature was maintained below $10^{\circ} \mathrm{C}$. Then the temperature of the reaction mixture was brought to $35^{\circ} \mathrm{C}$ slowly and 
maintained for $1 \mathrm{~h}$. Then it was cooled to $10^{\circ} \mathrm{C}$ and $\mathrm{NaOH}$ solution was added till alkaline.The resulting suspension was heated to $60{ }^{\circ} \mathrm{C}$ and allowed to cool to room temperature. It was filtered and washed with water.

\section{Synthesis of 2-chloro-N-(etheroaryl)acetamide(2a-} o)

In a solution of the appropriate aromatic amine (0.05) in $(30 \mathrm{ml}) \quad N, N-D M F$ equivalent moles of chloroacetylchloride was added slowly at room temperature and refluxed on heating mantle for two hours at temp $60{ }^{\circ} \mathrm{C}$. Excess of solvent was decanted off. The solid crystals was washed with ethanol and recrystalized with ethanol to get the pure compound.

\section{Synthesis of 2-(heteroarylimino) thiazolidin-4-ones} (3 a-o)

For the preparation of 2-(heteroarylimino) thiazolidin4-ones cyclization of intermediate 2-chloro- $\mathrm{N}$ (etheroaryl) acetamide was done with ammonium thiocyanate. 2-chloro- $N$-(etheroaryl) acetamide was dissolved in alcohol and equivalent amount of ammonium thiocyanate was added, refluxed for 1 hour, cooled, filtered, washed with alcohol, dried and finally recrystalized with alcohol to get the pure crystals.

\section{Synhthesis of 2-(heteroarylimino)-5-arylidine thiazolidin-4-ones (4a-o)}

2-(heteroarylimino) thiazolidin-4-ones was taken in ar.b.f containing alcohol. Indole aldehyde was then added to the flask followed by addition of piperidine as a catalyst. The mixture was then refluxed for 24 hrs. The mixture was then cooled and poured into crushed ice, in portions with constant stirring. Solid separated was then filtered and then washed with water. After drying it was then purified by recrystalization from ethanol and then melting point was noted.

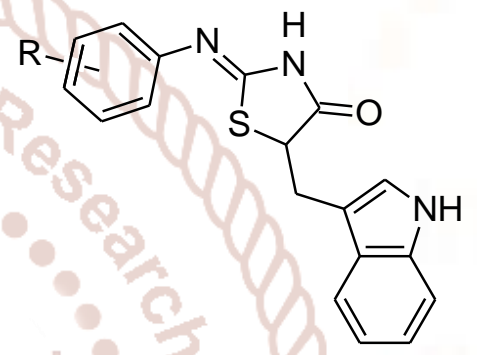

Physical data of 2-(arylimino)-5-(indole-2-yl-methylidene)-1,3-thiazolidine-4-one (4a-0)

\begin{tabular}{|c|c|c|c|c|c|c|}
\hline $\begin{array}{c}\text { S. } \\
\text { NO. }\end{array}$ & $\mathbf{R}$ & Molecular Formula & $\begin{array}{c}\text { Molecular } \\
\text { Weight }\end{array}$ & $\begin{array}{c}\text { Recrystalization } \\
\text { Solvent }\end{array}$ & $\begin{array}{c}\text { Melting } \\
\text { Point }\end{array}$ & $\begin{array}{c}\text { Yield } \\
(\%)\end{array}$ \\
\hline 4a & $\mathrm{H}$ & $\mathrm{C}_{18} \mathrm{H}_{13} \mathrm{~N}_{3} \mathrm{SO}$ & 319.38 & Ethanol & $265-267$ & 60 \\
\hline 4b & $\mathrm{o}-\mathrm{Cl}$ & $\mathrm{C}_{18} \mathrm{H}_{13} \mathrm{~N}_{3} \mathrm{SOCl}$ & 353.82 & Ethanol & $240-243$ & 62 \\
\hline $4 \mathrm{c}$ & $\mathrm{p}-\mathrm{Cl}$ & $\mathrm{C}_{18} \mathrm{H}_{12} \mathrm{~N}_{3} \mathrm{SOCl}$ & 353.82 & Ethanol & $232-235$ & 61 \\
\hline $4 \mathrm{~d}$ & $\mathrm{o}-$-methyl & $\mathrm{C}_{19} \mathrm{H}_{15} \mathrm{~N}_{3} \mathrm{SO}$ & 333.40 & Ethanol & $220-225$ & 65 \\
\hline 4e & m-methyl & $\mathrm{C}_{19} \mathrm{H}_{15} \mathrm{~N}_{3} \mathrm{SO}$ & 333.40 & Ethanol & $251-253$ & 62 \\
\hline $4 \mathrm{f}$ & p-methyl & $\mathrm{C}_{19} \mathrm{H}_{15} \mathrm{~N}_{3} \mathrm{SO}$ & 333.40 & Ethanol & $229-231$ & 72 \\
\hline $4 \mathrm{~g}$ & p-fluoro & $\mathrm{C}_{18} \mathrm{H}_{12} \mathrm{~N}_{3} \mathrm{FSO}$ & 337.37 & Ethanol & $276-278$ & 45 \\
\hline $4 \mathrm{~h}$ & o-nitro & $\mathrm{C}_{18} \mathrm{H}_{12} \mathrm{~N}_{3} \mathrm{O}_{3} \mathrm{SO}$ & 364.37 & Ethanol & $282-285$ & 79 \\
\hline $4 \mathrm{i}$ & m-nitro & $\mathrm{C}_{18} \mathrm{H}_{12} \mathrm{~N}_{4} \mathrm{O}_{3} \mathrm{~S}$ & 364.37 & Ethanol & $279-281$ & 67 \\
\hline $4 \mathrm{j}$ & o-Chloro, p-nitro & $\mathrm{C}_{18} \mathrm{H}_{11} \mathrm{~N}_{4} \mathrm{O}_{3} \mathrm{SCl}$ & 398.82 & Ethanol & $286-288$ & 47 \\
\hline $4 \mathrm{k}$ & p-methoxy & $\mathrm{C}_{19} \mathrm{H}_{15} \mathrm{~N}_{3} \mathrm{O}_{2} \mathrm{~S}$ & 349.40 & Ethanol & $242-244$ & 53 \\
\hline $4 \mathrm{l}$ & 2,5 -dimethyl & $\mathrm{C}_{19} \mathrm{H}_{15} \mathrm{~N}_{3} \mathrm{SO}$ & 333.40 & Ethanol & $222-225$ & 57 \\
\hline $4 \mathrm{~m}$ & o-bromo & $\mathrm{C}_{20} \mathrm{H}_{17} \mathrm{~N}_{3} \mathrm{SO}$ & 347.43 & Ethanol & $235-239$ & \\
\hline $4 \mathrm{n}$ & $\mathrm{H}$ & $\mathrm{C}_{18} \mathrm{H}_{14} \mathrm{~N}_{4} \mathrm{SO}$ & 334.39 & Ethanol & $265-267$ & 60 \\
\hline $4 \mathrm{o}$ & 2,4 dinitro & $\mathrm{C}_{18} \mathrm{H}_{12} \mathrm{~N}_{6} \mathrm{O}_{5} \mathrm{~S}$ & 424.39 & Ethanol & $267-270$ & 57 \\
\hline
\end{tabular}

Table:1 Physical and analytical data of compounds (4 a-o)

\section{Biological and Pharmacological Studies}

Compounds (4a-o) were tested for their antiinflammatory and analgesic activities. The experiment was performed with albino mice of either sex, excluding pregnant females, of 60-90 days weighing $30-40 \mathrm{~g}$. Food (chaw pallet) and water was given to the animals ad libitum. The test compounds were dissolved in propylene glycol. Diclofenac and phenylbutazone were used as reference drugs for the comparison of anti-inflammatory and analgesic activities. 


\section{General methods for in vivo activity}

Swiss albino mice weighing 30-40 g were obtained from disease free animal house, CCS Haryana Agricultural University, Hisar Haryana, (India). The animals were housed in animal house Institute Of Pharmaceutical Sciences, Kurukshetra University, Kurukshetra, Haryana, in polycarbonate cages in a room maintained under controlled room temperature $22 \pm{ }^{\circ} \mathrm{c}$, relative humidity $60-70 \%$ and provided with food and water ad libitum. All the experimental procedures and protocols used in the study were reviewed by the institutional animal ethics committee (Regn. No. 563/02/a/CPCSEA) and were in accordance with guidelines of the CPCSEA, Ministry of forests and environment, govt. of India. The animals were deprived of food for $24 \mathrm{~h}$ before experimentation but allowed free access to water throughout. All studies were carried out by using required number of groups of animals for analgesic activity.

\section{Evaluation of anti-inflammatory activity}

Inflammation is a fundamental pathophysiological response designed to eliminate any noxious stimulus introduced into the host. Such noxious stimuli include radiant, chemical, physical infectious and immune provocation, characterized by redness; inflammation sequence can be summarized as follows:

1. Initial injury to cause release of inflammatory mediators such as histamine, serotonin, leukokinins, slow reaching substance-A(SRS-A), lysosomal enzyme, lymphokinins $\mathrm{N}$ and prostaglandins.

2. Mediators cause vasodilation.

3. This cause increased vascular permeability and exudation occurs.

4. Proliferation of connective tissue cells occurs.

5. Inflammation is known to cause various rheumatic diseases such as rheumatoid arthritis, osteoarthritis, gout, neoplasms and various allergic reactions. The search for new and effective treatment requires availability of adequate screening tests. Although no model adequately reflects the events, which occure in human arthritic conditions, several in vivo and in vitro assays are used.

The most commonly used in vivo animal assay measures the ability of anti-inflammatory agents:

1. To inhibit edema induced in the rat paw by carrageenan.
2. To inhibit adjuvant arthritis in rats induced by Mycobacterium butyricum or M. Tuberculosis.

3. To inhibit granuloma formation usually induced by the implantation of a cotton pellet beneath the abdomen of rats.

4. To inhibit erythema of guinea pig skin as a result of exposure to ultra violet radiation.

5. In vitro techniques include the ability of antiinflammatory agents to stabilize erythrocyte membranes or more commonly to inhibit the biosynthesis of prostaglandins, particularly in cultured human synoviocyes and chondrocytes.

\section{Carrageenan induced paw edema}

Carrageenan induced paw edema is the most commonly used method in experimental pharmacology. Carrageenan is a sulphated polysaccharide obtained from sea weed (Rhodophyceae), and by posing he release of histamine, 5-hydroxy tryptamine, bradykinin and prostaglandins, it produces inflammation and edema.

\section{Experimental protocol}

The present method depends on the inhibition of edema caused by carrageenan. The edema is measured by plethysmometer.

Animals: The studies were carried out on healthy Wister albino rats weighing between $180-250 \mathrm{gm}$. The animals were divided into different of groups of 6 animals. The animals were subjected to fasting before experimentation.

Drugs: Carrageenan: $1 \% \quad w / v$ suspension was prepared and injected $0.1 \mathrm{ml}$ subcutaneously (underneath planter region)

Diclofenac sodium: Dose $50 \mathrm{mg} / \mathrm{kg}$ body weight of rats and given orally.

Routes of administration: The compounds and standard drug were suspended in $0.5 \%$ carboxymethyl cellulose. Standard drug was given intraperitoneally and the test compounds were given by oral route. Crrageenan suspension in distilled water was given to the right hind paw by subcutaneous (s.c.)route.

Plethysmometer employed was Model -7140, UgoBasile, Italy.

The anti-inflammatory activity of synthesized compounds using carrageenan-induced paw edema 
International Journal of Trend in Scientific Research and Development (IJTSRD) ISSN: 2456-6470

was studied according to method of winter et al,1962.The animals were divided into different groups each containing of 6 rats. Control group received normal saline : tween 80 (95:5), the standard group received diclofenac sodium $50 \mathrm{mg} / \mathrm{kg}$, i.p. and the test group received the synthesized compounds at the dose of $50 \mathrm{mg} / \mathrm{kg}$ :p.o. Thirty minutes after administration of test and standard drugs, $0.1 \mathrm{ml}$ of $1 \% \mathrm{w} / \mathrm{v}$ of carrageenan suspension in normal saline was injected to all animals in the left hind paw(plantar region). The paw volume, up to the tibioarsal articulation, was measured using a plethysmomeer (model 7140, UgoBasile, Italy). The measures were determined at zero hours (before carrageenan injection) and 30, 60, 90 and $120 \mathrm{~min}$ after drug treatment. Result is compiled in table.

The percentage inhibition of inflammation was calculated for standard drug and test compounds by following formula. Edema $(\Delta \mathrm{T})$ and inhibition rate $(\mathrm{I})$ were calculated as followed:

The percentage inhibition of inflammation was calculated for standard drug and test compounds by following formula. Edema $(\Delta \mathrm{T})$ and inhibition rate (I) were calculated as follows:

$$
\Delta \mathrm{T}=\mathrm{T}_{\mathrm{t}}-\mathrm{T}_{\mathrm{o}}
$$

Percentage Inflammation $=\Delta \mathrm{T} / \mathrm{T}_{\mathrm{O}} \times 100$

Percentage Inhibition $=100$-Percentage Inflammation Where $T_{t}=$ the right hind paw thickness at time $t$, $\mathrm{T}_{\mathrm{o}}=$ the right hind paw thickness before sub-planter injection of carrageenan.

Statistical Analysis: All the results were expressed as mean \pm Standard Mean (SEM). Data was analyzed using one way ANOVA by Dunnett's ' $t$ ' test.

Effect of carrageenan induced paw edema volume in mice

\begin{tabular}{|c|c|c|c|c|c|}
\hline \multirow{2}{*}{ S. No } & \multirow{2}{*}{$\begin{array}{l}\text { Treatment } \\
\text { (Comp. No.) }\end{array}$} & \multicolumn{4}{|c|}{ Paw edema volume Mean \pm SEM ( $\%$ inhibition) } \\
\hline & & 30 min. & 60 min. & 90 min. & 120 min. \\
\hline 1 & Control & $0.32 \pm 0.008$ & $0.42 \pm 0.007 \mathrm{OU}$ & $0.45 \pm 0.007$ & $0.48 \pm 0.003$ \\
\hline 2 & Standard & $0.21 \pm 0.003(34.38)$ & $0.26 \pm 0.01(38.10)$ & $0.27 \pm 0.003(40)$ & $0.33 \pm 0.012(31.25)$ \\
\hline 3 & PH-1 & $0.26 \pm 0.003(18.18)$ & $0.33 \pm 0.014(21.43)$ & $0.34 \pm 0.01(24.44)$ & $0.47 \pm 0.007(29.17)$ \\
\hline 4 & PH-2 & $0.25 \pm 0.01(21.88)$ & $0.32 \pm 0.02(23.81)$ & $0.33 \pm 0.005(26.67)$ & $0.33 \pm 0.009(31.25)$ \\
\hline 5 & $\mathrm{PH}-3$ & $0.27 \pm 0.01(15.62)$ & $0.30 \pm 0.01(28.57)$ & $0.33 \pm 0.008(26.67)$ & $0.28 \pm .006(41.67)$ \\
\hline 6 & $\mathrm{PH}-4$ & $0.28 \pm 0.02(12.5)$ & $0.32 \pm 0.01(23.81)$ & $0.33 \pm 0.005(26.67)$ & $0.26 \pm 0.007(45.83)$ \\
\hline 7 & PH-5 & $0.28 \pm 0.02(12.5)$ & $0.25 \pm 0.01(40.48)$ & $0.26 \pm 0.007(42.22)$ & $0.31 \pm 0.01(35.67)$ \\
\hline 8 & PH-6 & $0.26 \pm 0.001(18.75)$ & $0.28 \pm 0.02(33.33)$ & $0.27 \pm 0.005(40)$ & $0.28 \pm 0.01(42.47)$ \\
\hline 9 & PH-7 & $0.26 \pm 0.003(18.75)$ & $0.32 \pm 0.03(23.81)$ & $0.33 \pm 0.016(26.67)$ & $0.33 \pm 0.006(31.25)$ \\
\hline 10 & PH-8 & $0.21 \pm 0.003(34.38)$ & $0.23 \pm 0.01(45.24)$ & $0.26 \pm 0.007(42.22)$ & $0.19 \pm 0.014(61.23)$ \\
\hline 11 & PH-9 & $0.23 \pm 0.01(28.12)$ & $0.24 \pm 0.01(42.86)$ & $0.24 \pm 0.004(46.67)$ & $0.28 \pm 0.006(42.33)$ \\
\hline 12 & PH-10 & $0.22 \pm 0.008(31.25)$ & $0.31 \pm 0.008(26.19)$ & $0.32 \pm 0.01(28.89)$ & $0.26 \pm 0.005(45.83)$ \\
\hline 13 & PH-11 & $0.29 \pm 0.008(9.38)$ & $0.28 \pm 0.03(33.33)$ & $0.27 \pm 0.003(40)$ & $0.30 \pm 0.01(39.17)$ \\
\hline 14 & PH-12 & $0.30 \pm 0.03(6.12)$ & $0.32 \pm 0.008(23.81)$ & $0.33 \pm 0.01(26.67)$ & $0.28 \pm 0.003(41.67)$ \\
\hline 15 & PH-13 & $0.26 \pm 0.01(18.75)$ & $0.26 \pm 0.02(38.10)$ & $0.26 \pm 0.008(42.22)$ & $0.47 \pm 0.01(29.17)$ \\
\hline 16 & PH-14 & $0.23 \pm 0.01(28.12)$ & $0.33 \pm 0.01(21.43)$ & $0.34 \pm 0.006(24.44)$ & $0.31 \pm 0.006(33.46)$ \\
\hline 17 & PH-15 & $0.29 \pm 0.02(9.38)$ & $0.25 \pm 0.006(40.48)$ & $0.25 \pm 0.007(44.44)$ & $0.33 \pm 0.005(31.25)$ \\
\hline
\end{tabular}

Paw edema volume as Mean \pm SEM, $n=6$ animals.

$* \mathrm{P}<0.01, * * \mathrm{P}<0.05$ animal compared to control 


\section{Evaluation of analgesic activity}

Agents that decrease pain are referred to as analgesics (pain killer). They act by increasing the threshold to pain stimuli. The commonly used analgesics are aspirin, paracetamol (non-narcotic type), and morphine (narcotic type). The non-steroidal antiinflammatory agents have primarily site of action, are useful for mild to moderator pain.

Painful reaction in experimental animals can be produced by applying noxious (unpleasant) stimuli such as radiant heat (as a source of pain), chemical irritants (such as acetic acid and bradykinin) and physical pressure (tail compression).

In the laboratory, commonly use procedures are:-

1. Acetic acid induced writhing

2. Tail flick (tail withdrawal from radiant heat) method using analgesiometer.

3. Hot plate (jumping from hot plate at $55^{\circ} \mathrm{C}$ ) method.

4. The present method based on Acetic acid induced writhing and the reaction was measured by no of writhes decreased after the induction of drug.

\section{Experimental protocols:-}

Procedure

The analgesic activities were measured against chemical and thermal stimulus. For analgesic activity, the animals were divided in to groups consisting of 6 mice each. The control group received normal saline: tween 80 (95:5); p.o. The standard group received nimusulide $4 \mathrm{mg} / \mathrm{kg}$; ip and the test groups received the synthetic compounds at a dose of $50 \mathrm{mg} / \mathrm{kg}$; p.o.

\section{Acetic acid induced abdominal writhing test}

Nociception was induced by an intraperitoneal (IP) injection of acetic acid $(1.0 \%), 0.1 \mathrm{ml} / 10 \mathrm{~kg}$. All the groups of six mice each pretreated with normal saline: CMC (1.0\%), nimusulide $4 \mathrm{mg} / \mathrm{kg}$; i.p. and test compounds received acetic acid (IP) 30 min later. The number of stretching or writhing was recorded from 5 min to $15 \mathrm{~min}$. results of this study have been summarized in table

The percentage protection was calculated by following formula:

Percentage protection $=$ No of writhes in test No of writhes in control

Table: 3 Effect of compounds on acetic acid induced writhing in mice

\begin{tabular}{|c|c|c|c|}
\hline S. No. & $\begin{array}{c}\text { Treatment } \\
(\text { Comp. No. })\end{array}$ & $\begin{array}{c}\text { Dose } \\
(\mathrm{mg} / \mathrm{kg})\end{array}$ & $\begin{array}{c}\text { No. of Writhes } \\
\text { Mean } \pm \text { SEM (\% inhibition) }\end{array}$ \\
\hline 1 & Control & $50 / 0$ & $31.52 \pm 0.34$ \\
2 & Standard & 50 & $10.40 \pm 0.14(60.23)$ \\
3 & PH-1 & do 4 & $6=621.10 \pm 0.69(29.17)$ \\
4 & PH-2 & do & $18.17 \pm 0.22(41.67)$ \\
5 & PH-3 & do & $14.50 \pm 0.26(52.34)$ \\
6 & PH-4 & do & $17.29 \pm 0.27(43.17)$ \\
7 & PH-5 & do & $17.18 \pm 0.35(45.63)$ \\
8 & PH-6 & do & $16.38 \pm 0.22(46.16)$ \\
9 & PH-7 & do & $19.32 \pm 0.36(36.74)$ \\
10 & PH-8 & do & $9.35 \pm 0.28(68.74)$ \\
11 & PH-9 & do & $17.48 \pm 0.31(42.44)$ \\
12 & PH-10 & do & $11.71 \pm 0.12(62.34)$ \\
13 & PH-11 & do & $19.50 \pm 0.44(37.42)$ \\
14 & PH-12 & do & $15.29 \pm 0.38(51.45)$ \\
15 & PH-13 & do & $19.53 \pm 0.42(36.24)$ \\
16 & PH-14 & do & $17.55 \pm 0.58(43.56)$ \\
17 & PH-15 & do & $22.17 \pm 0.47(28.67)$ \\
\hline
\end{tabular}

No of writhes expressed as Mean \pm SEM, $\mathrm{n}=6$ animals 


\section{Docking}

Methods for predicting modes of small organic molecules to protein receptors are widely used within drug discovery efforts. Docking of a ligand is typically achieved by generating a number of orientations ( or poses) of a ligand within the active site, and scoring of poses to identify one or more that closely approximate the bioactive conformation determined by X-ray crystallography Docking algorithms are also used for identifying putative binders from virtual chemical databases and for estimating the binding affinity of protein-ligand complexes Molecular docking can also be used to test possible hypotheses before conducting costly laboratory experiments. Molecular docking programs predict how a drug candidate binds to a protein target. This software consists of two core components:

1. A search algorithm, sometimes called an optimization algorithm. The search algorithm is responsible for finding the best conformations of the ligand, a small drug-like molecule and protein system. A conformation is the position and orientation of the ligand relative to the protein. In flexible docking the conformation also contains information about the internal flexible structure of the ligand - and in some cases about the internal flexible structure of the protein. Since the number of possible conformations is extremely large, it is not possible to test all of them. Therefore, sophisticated search techniques have to be applied. Examples of some commonly used methods are Genetic Algorithms and Monte Carlo simulations.

2. An evaluation function, sometimes called a score function. This is a function providing a measure of how strongly a given ligand will interact with a particular protein. Energy force fields are often used as evaluation functions. These force fields calculate the energy contribution from different terms such as the known electrostatic forces between the atoms in the ligand and in the protein, forces arising from deformation of the ligand, pure electron-shell repulsion between atoms and effect from the solvent in which the interaction takes place.

Docking studies have been performed with cox-2 inhibitory activity data for a set of 15 indole derivatives which have been synthesized. The activity was expressed as \%age inhibition The enzyme was expressed in E.coli and purified by immobilized metal affinity chromatography followed by ion exchange chromatography (191). The basic chemical structure of indole derivatives possessing cox-2inhibitory activity is shown in figure

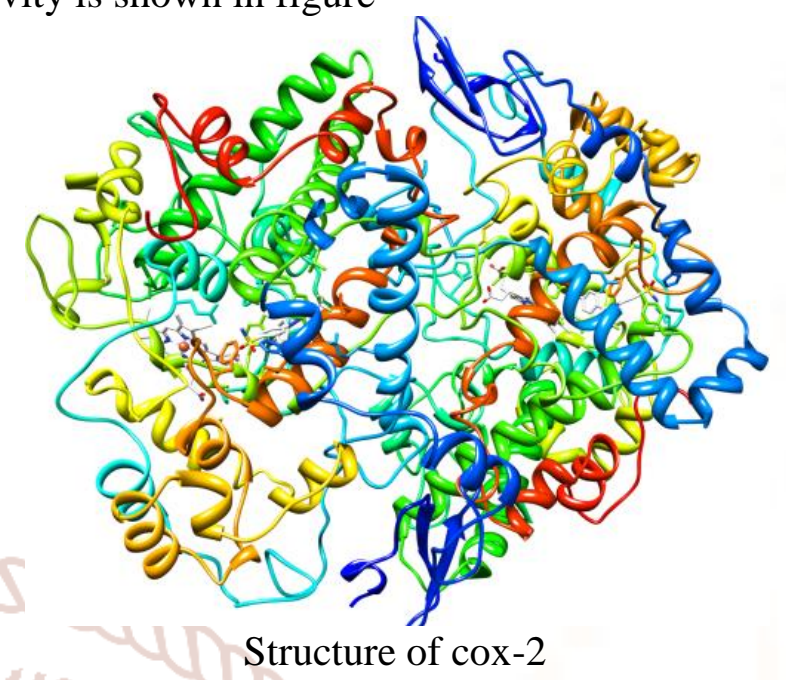

\section{Ligand Preparation}

The structures of molecules were built using Maestro 8.5.207 and converted to 3D structure from the $2 \mathrm{D}$ structure using LigPrep version 2.2 (200). LigPrepis a robust collection of tools designed to prepare high quality, all-atom 3D structures for large numbers of drug-like molecules, starting with the $2 \mathrm{D}$ or $3 \mathrm{D}$ structures in SD or Maestro format. The resulting structures are saved in Maestro format. The simplest use of LigPrep produces a single, low-energy, 3D structure with correct chiralities for each successfully proposed input structure. While performing this step, chiralities were determined from 3D structure and original states of ionization were retained. Tautomers were generated using MacroModel method discarding current conformers. The conformational space was searched using the Monte Carlo (MCMM) method as implemented in MacroModel version 9.6. All rotatable single bonds were included in the conformational search. Each search was continued until the global energy minima were found at least 10 times. The energy minimizations were carried out using the truncated newton conjugate gradient algorithm (TNCG) and the MMFFs force field as implemented in MacroModel. The conformational searches were done for aqueous solution using the generalized Born/solvent accessible surface (GB/SA) continuum solvation model (201).

\section{Protein Preparation}

The cox-2 (PDB ID 2P3G) X-ray structures were accessed from the protein data bank (PDB). The protein structures were prepared using the protein preparation wizard in Maestro. In this step, bond 
orders were assigned, all hydrogens in the structure were added, and bonds to metals were deleted and the formal charge on the metal \& the neighbouring atoms were adjusted that were more than the $5 \AA$ specified distance. Generate Het states option was used for predicting ionization and tautomeric states of the het group at $\mathrm{pH}$ 7. The next stage of protein preparation was to optimize the hydrogen bond network by reorienting hydroxyl group, water molecules, and amide groups of ASN and GLN, and selecting appropriates states and orientation of the rings in the residues. The final step in the protein preparation process was to refine the structure, with a restrained minimization. Their task was initiated in the Impref minimization with the $0.3 \AA$ RMSD for the OPLS_2005 force field.

\section{Docking}

Glide searches for favorable interactions between ligand molecules and the receptor protein. Grids were generated using Glide version 5.0 following the standard procedure recommended by Schrödinger. Grid generation defined the active site of the protein and generated the electrostatic grid. No constraints were included in the grid files. The shape and properties of the receptor were represented on a grid by several different sets of field that provide progressively more accurate scoring of the ligand poses. For receptors that adopt more than one conformation on binding, grids were prepared for each conformation, to ensure that possible actives were not missed. Ligand molecule was picked so that it can be excluded from the grid generation with van der Waals radius scaling 1.00 and partial charge cutoff of 0.25 . The compounds were docked using Glide with standard settings in standard precision (XP) mode. The docked poses discussed here were not necessarily the highest scoring, but were selected as the highest scoring pose with a reasonable conformation and binding mode as judged by the modeler.

\section{Calculation of the conformational energy penalty}

The docked conformation was minimized with MacroModel using default restraining force constant of $100 \mathrm{~kJ} / \mathrm{mol}$. This allowed the docked conformations to adjust to the MMFFs force field. This relaxation does not change the conformation as RMSE between the docked and relaxed structures were $<0.1 \AA$. The conformational energy penalty of the docked conformations was calculated by subtracting the internal (steric) energy of the preferred conformation in aqueous solution (i.e. the energy of the global energy minimum in solution excluding the hydration energy) from the calculated energy of the docked conformation. Since the conformational ensemble was represented by only the global energy minima, entropy effects have not been taken into account. For flexible molecules this leads to an underestimation of the energy penalty. A limit of 3 $\mathrm{kcal} / \mathrm{mol}(12.6 \mathrm{~kJ} / \mathrm{mol})$ for acceptable energy penalties was imposed as recommended by Boström et al (202).

\section{Results and Discussion}

The crystallographic structures of COX-2 revealed the presence of a large hydrophobic pocket in COX-2 in the hinge region of the ATP site. The smaller $\mathrm{Val}_{523}$ residue in $C O X-2$ allows access to a hydrophobic side-pocket in the enzyme (which $\mathrm{Ile}_{523}$ sterically hinders). The first step accounts for the contact of the inhibitor with the gate of the hydrophobic channel (called the lobby region). The second step could account for the movement of the inhibitor from the lobby region to the active site of the COX enzyme. The last step probably represents repositioning of the inhibitor at the active site, which leads to strong interactions of the inhibitor and the amino acids of the side pocket.Docking studies may be helpful in elucidating the mechanisms of COX-2 receptor-ligand interactions. Docking studies reveal the interactions of the ligands with binding site of the enzyme or receptor involved. The indolederivatives were embedded in the hydrophobic pocket (Fig. 5.1) formed by the amino acids LEU 141, GLU 139, GLU 145, ASP 142, ASP 207, LYS 188 and ASN 191. Docking studies reveals following information with respect to cox-2 inhibitors:

Glide score (docking score) for the docked poses plotted against the cox-2inhibiting affinity. 


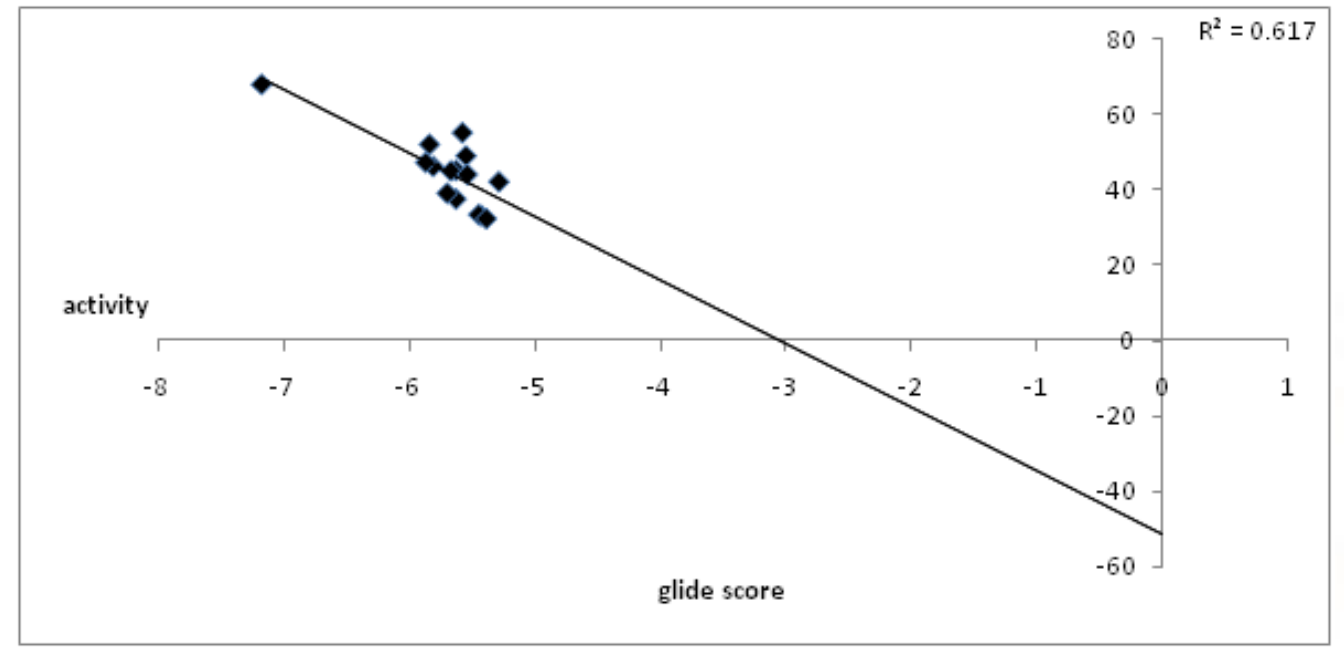

\section{Conclusion:}

Compounds bearing electron withdrawing substitutions at phenyl group have more significant activities as compared to the compound with electron donating substituents.

Compounds $4 \mathrm{o}$ have a 2-chloro and 4 - nitro and $4 \mathrm{j}$ having nitro at $2 \& 4$ of phenyl group as substituent exhibited most potent analgesic, anti-inflammatory and antimicrobialactivities. Thus the obtained biological results clearly indicate that compounds which showed maximum anti-inflammatory activity also exhibit potent analgesic and antimicrobial activity. Among the tested compounds in the series $4 \mathrm{o}, 4 \mathrm{i}, 4 \mathrm{j}$ show good activity against microorganisms.

Docking studies have been performed with COX-2 using 15 indole derivatives which have been synthesized. Maximum Glide score was obtained for compound 40 having a value of -7.42 . This compound showed 1 interaction with the enzyme. Good correlation was observed between docking score and analgesic activity $\left(\mathrm{r}^{2}=0.746\right)$ and anti-inflammatory $\left(\mathrm{r}^{2}\right.$ $=0.675$ ).

The proposed 3-D QSAR model can be useful to identify new promising compounds as P-gp inhibitors in large 3-D database of molecules.

Acknowledgement:-The work was supported by Rajendra institute of technology and sciences, Sirsa Haryana and KUK, Kurshetra.

\section{References}

1. Zhao, F., Liu, N., Zhan, P., Jiang, X. \& Liu, X. Discovery of HCV NS5B thumb site I Inhibitors: core-refining from benzimidazole to indole scaffold. Eur. J. Med. Chem. 94, 2015, 218-228
2. Mohammad, H. et al. Synthesis and antibacterial evaluation of a novel series of Syntheticphenylthiazole compounds against methicillin-resistant Staphylococcus aureus (MRSA). Eur. J. Med. Chem. 94, 2015, 306-316

3. G. A. Khan, J. A. War, G. A. Naikoo, U. J. Pandit, R. Das, Porous CuOcatalysed green Synthesis of some novel 3-alkylated indoles as potent antitubercular agents, J. Saudi Chem. Soc. 64, 2015, 189-192

4. R. P. Karuvalam, R. Pakkath, K. R. Haridas, R. Rishikesan, N. S. Kumari, Synthesis, characterization and QSAR studies of new $(1 \mathrm{H}-$ indol-3-yl)-alkyl-3-(1H-indol-3-yl) propanamide derivatives as possible antimicrobial and antitubercular agents, Med. Chem. Res.22, 2013, 4437-4454

5. Giraud, F. et al. Design, synthesis and evaluation of 3-(imidazol-1-ylmethyl) indolesas antileishmanial agents. Part II. J. Enzyme Inhib. Med. Chem. 24, 2009, 1067-1075

6. R. Gali, J. Banothu, R. Gondru, R. Bavantula, Y. Velivela, P. A. Crooks, One-pot multicomponent synthesis of indole incorporated thiazolylcoumarins and their antibacterial, anticancer and DNA cleavage studies, J. Bioorg. Med. Chem. Lett. 25, 2015, 106-112

7. S. Naureen, S. Noreen,A. Nazeer, M. Ashraf, U. Alam, M. A. Munawar, M. A. Khan, Triarylimidazoles-synthesis of 3-(4,5-diaryl-1Himidazol-2-yl)-2-phenyl-1H-indole derivativesas potent a-glucosidase inhibitors, Med. Chem. Res. 24, 20151586-1595 
8. Wang, Y. et al. Structure-based design, synthesis, and biological evaluation of isatinderivatives as potential glycosyltransferase inhibitors. Chem. Biol. Drug Des. 84, 2014, 685-696

9. Q. Guan, C. Han, D. Zuo, M. Zhai, Z. Li,Q. Zhang, Y. Zhai, X. Jiang, K. Bao, Y. Wu, W. Zhang, Synthesis and evaluation of benzimidazolecarbamates bearing indole moieties for antiproliferative and antitubulin activities, Eur. J. Med. Chem. 87, 2014, 306-315

10. C. Desiree, Schuck, A. K. Jordao, M. Nakabashi, A. C. Cunha, V. F. Ferreira, C. R. S. Garcia, Syntheticindole and melatonin derivatives exhibit ant malarial activity on the cell cycle of the human malaria parasite Plasmodium falciparum, Eur. J. Med. Chem. 78, 2014, 375-382

11. Zhang, M. Z. et al. Synthesis and antifungal activity of 3-(1,3,4-oxadiazol-5-yl)-indoles and 3(1,3,4-oxadiazol-5-yl)methyl-indoles. Eur. J. Med. Chem. 63, 2013, 22-32

12. Penthala, N. R., Yerramreddy, T. R. \& Crooks, P. A. Synthesis and in vitro screening of novel Nbenzyl aplysinopsin analogs as potential anticancer agents. Bioorg. Med. Chem. Lett. 21, 2011, 1411-1413

13. Andreani, A. et al. Imidazo [2,1-b] thiazoleguanidinylhydrazones as RSK2 inhibitors. Eur. J. Med. Chem. 46, 2011, 4311-4323

14. Xu, H., Wang, Q. \& Yang, W. B. Antifungal activities of some indole derivatives. $\mathrm{Z}$. Naturforsch C. 65, 2010, 437-439

15. J. S. Biradar, B. S. Sasidhar, R. Parveen, Synthesis, antioxidant and DNA cleavage activities of novel indole derivatives, Eur. J. Med. Chem.45, 2010, 4074-4078

16. Geronikaki, A.; Eleftheriou, P.; Vicini, P.; Alam, I.; Dixit, A and Sexena, A. K. ;J. Med. Chem. 5, 2008, 221-522

17. Akbari, J. D.; Mehat, K. B.; Pathak, S. J and Joshi, H. S, Ind. J. Chem. 47B, 2008, 477-480

18. Poulsen, A; William, A; Lee, A; Blanchard, S; Teo, E; Deng, W; Tu, N; Tan, E; Sun, E; Goh, K. L; Ong, W. C; Ng, C. P; Goh, K. C; Bonday, Z. J. Comput. Aided Mol. Des.22, 2008, 897-906 